\title{
ESTRUTURAS ANATÔMICAS E PATOLÓGICAS QUE PODEM SER CONFUNDIDAS COM ATEROMAS CALCIFICADOS NAS RADIOGRAFIAS PANORÂMICAS
}

Ana Luiza ROCHA; Cristiane MENIN; Anna Paola CARTA; Juliana Garcia Camilo MIRANDA; Mariliani Chicarelli da SILVA.

A radiografia panorâmica é um dos exames complementares mais utilizados pelo Cirurgião Dentista atualmente, podendo ser útil na conclusão de vários diagnósticos. Estudos mostram que é capaz de possibilitar a identificação de ateromas calcificados na artéria carótida. As calcificações aparecem como uma massa ou duas linhas radiopacas na região do pescoço no nível da borda inferior da terceira vértebra cervical (C3), acima ou abaixo do osso hióide. A aterosclerose na bifurcação da carótida é a causa mais comum da ocorrência de um acidente vascular cerebral (AVC) que muitas vezes pode levar à morte ou à diferentes condições de invalidez. É dever do Cirurgião Dentista, como promotor de saúde, ao analisar uma radiografia panorâmica de rotina, estar sempre atento aos sinais existentes, para que possa contribuir com o diagnóstico precoce da doença. Este trabalho visa dar ênfase ao diagnóstico diferencial, uma vez que existem estruturas anatômicas e patologias que são freqüentemente confundidas com ateromas calcificados. 